SCIENTIFIC REPORT

\title{
Observations on the management of Coats' disease: less is more
}

\author{
Robert S Adam, Peter J Kertes, Wai-Ching Lam
}

Br J Ophthalmol 2007;91:303-306. doi: 10.1136/bjo.2006.103382

Background: In this article we share our experience of treating various severities of Coats' disease and focus on optimal therapy for advanced disease.

Methods: Retrospective chart review of 10 patients treated with varied techniques including intraocular surgery, cryopexy and/ or laser photocoagulation.

Results: Nine patients were male. At presentation the average age was 4.6 years (range 21 months -7 years), the average number of retinal quadrants involved with telangiectasia was 2.7 (range 1-4, median 3), eight of the 10 patients had retinal detachment, six of these being total, and all patients had macular involvement with either exudate or fibrosis. Average follow-up was 2.3 years (range $1-4.5$ years). The best visual outcomes were observed in patients who presented with less severe disease. For example, the only four patients to maintain ambulatory vision all presented without total retinal detachment, two or fewer quadrants of retinal telangiectasia and a visual acuity better than light perception. No patient developed secondary angle closure glaucoma, and all patients have kept a cosmetically acceptable eye.

Conclusion: In this limited series, visual outcomes in the setting of advanced Coats' disease are largely dependent on disease severity and visual status at the time of presentation. Minimally invasive surgery with vitreous infusion through the pars plana, combined with external drainage of subretinal fluid together with cryotherapy and/or laser photocoagulation is sufficient to effect retinal re-attachment and prevent loss of the eye.

n 1908 George Coats first described the retinal vascular abnormalities that are the hallmark of Coats' disease. ${ }^{1}$ This idiopathic, generally unilateral condition is characterised by telangiectatic and aneurysmal changes of the retinal vessels, often described as "light bulb telangiectasia", associated with large amounts of yellowish subretinal exudate. ${ }^{23}$ It most often affects males in the first or second decade of life. Although spontaneous regression has been reported, progression is the rule and patients often present with leukocoria due to exudative, bullous retinal detachment. ${ }^{45}$

Limited treatment options existed before the widespread use of vascular ablative techniques, and enucleation was common in order to prevent or manage the development of painful neovascular glaucoma. ${ }^{56}$ Furthermore, advanced disease can resemble exophytic retinoblastoma. Because the risk of misdiagnosis was high and the probability of preserving vision low, such eyes were often enucleated at presentation. ${ }^{58}$ Modern diagnostic modalities have allowed clinicians to rule out retinoblastoma with high sensitivity and consequently surgeons began to employ various treatments over the past few decades. ${ }^{9}{ }^{10}$

No prospective, randomised trials have been conducted in order to assess what is the optimal treatment for re-attachment of the retina in advanced cases. We present here the results of our experience treating 10 patients with Coats' disease, several of whom had advanced disease, as defined by greater than two quadrants of retinal telangectasia with retinal detachment.

\section{MATERIALS AND METHODS}

The operating room roster of all paediatric patients seen by WCL at The Hospital for Sick Children in Toronto between 1999 and 2004 was reviewed and all patients with a diagnosis of Coats' disease were identified. Diagnosis was based upon a combination of physical examination and/or fundus photography, fluorescein angiography, CT scan and analysis of intraoperative subretinal fluid. Patient characteristics are summarised in table 1 .

A total of 10 patients (10 eyes) were identified, eight of whom presented with extensive exudative retinal detachment managed surgically under general anaesthesia.

Patients 1 and 3 were born prematurely at 36 weeks' gestational age but were at low risk for retinopathy of prematurity. Patient 8 had a father and an uncle with retinitis pigmentosa, however the patient has shown no signs of this disease in the fellow eye.

\section{Surgical technique}

Six of these eight patients with extensive exudative retinal detachment (patients 1-6) were treated with minimally invasive surgery that involved establishment of a pars plana vitreous infusion line of balanced salt solution, external drainage by way of a posterior sclerotomy with subretinal fluid drainage and cryopexy treatment of telangiectasia with a double freeze-thaw technique. One of these patients (patient 1) received trans-pupillary diode laser treatment 1 month postoperatively to a fibrovascular lesion with fluorescein leakage causing recurrent, inferior retinal detachment (fig 1A,B). Patient 6, who was discharged with persistent telangiectasia, was treated with a second operation by his original surgeon. This involved lensectomy, vitrectomy, membrane peeling with internal drainage, laser photocoagulation and silicone oil to correct persistent retinal detachment 4 months after the first procedure.

Two of the 10 patients (patients 7 and 8) were treated with slightly more involved surgery including standard three-port vitrectomy and membrane peeling with posterior sclerotomy and external drainage of subretinal fluid. Patient 7 had an extensive macular subretinal fibrovascular membrane that was removed through a retinotomy, as well as air-fluid exchange with $15 \% \mathrm{C}_{3} \mathrm{~F}_{8}$ and indirect argon laser photocoagulation of peripheral telangiectasia. The telangiectasia in patient 8 were treated with the double freeze-thaw cryopexy technique. No retinotomy was required as the membrane was preretinal. Patient 8 was treated with argon laser photocoagulation on

Abbreviations: HM, hand motions; LP, light perception; ?LP, presumed light perception; NLP, no light perception 
three occasions during the first 3 postoperative months due to persistent telangiectasia with subretinal fluid (fig 2A,B). All patients received subconjunctival injection of Solu-medrol and gentamycin and various combinations of topical antibiotics, steroids and mydriatics.

Finally, the two patients who did not have a retinal detachment at presentation (patients 9 and 10) were treated with either cryopexy (double freeze-thaw) or laser photocoagulation of telangiectasia in a single quadrant. In all cases cryopexy or photocoagulation was delivered with sufficient power and duration to cause closure and/or significant shrinking of the anomalous vessels. Patient care from diagnosis to follow-up during the postoperative period was performed by one of the authors (WCL). Patients have since been followed at least annually by the surgeon or in some cases by their primary eye care practitioner with comprehensive eye examinations and fluorescein angiography as needed. Follow-up at the time of writing ranged from 1 to 4.5 years (average 2.3 years). Occlusive patching treatment was not prescribed for any patient.

\section{RESULTS}

The details and characteristics of the patients are summarised in table 1 . Nine of the 10 patients were male. At presentation the average age was 4.6 years (range 21 months-7 years).

\section{Visual acuity}

In the subgroup treated with minimally invasive surgery that involved establishment of a pars plana vitreous infusion line of balanced salt solution, external subretinal fluid drainage by way of a posterior sclerotomy and cryopexy (patients 1-6), two patients presented with no light perception (NLP), two with presumed light perception (?LP), one with light perception (LP) and one with 20/300 vision. Four of these patients are now NLP (patients 2-5) and one has hand motions (HM) vision (patient 6). Only one patient in this group (patient 1), who presented with 20/300 ambulatory vision, has maintained 20/60 vision. This patient also had only two quadrants of retinal involvement and received one session of postoperative trans-pupillary diode laser treatment (fig lA,B). Patient 6, who presented with NLP vision and now has HM visual acuity, was treated with a second more invasive operation. Patients 7 and 8 were treated with surgery involving vitrectomy and membrane peeling. Patient 7 , in whom only two retinal quadrants were affected, presented with vision of counting fingers at 1 foot $(30.48 \mathrm{~cm})$ and maintained 20/200 vision. Patient 8, who presented with LP vision, is now NLP despite receiving three postoperative laser treatments (fig 2A,B). Patient 9, who was treated with one session of cryopexy and no other surgery, presented with counting fingers at 4 feet $(1.23 \mathrm{~m})$ and has maintained 20/300 vision. Patient 10 presented with $20 / 40^{-2}$ vision ??but did not receive treatment until the vision had declined to 20/400. Two sessions of laser photocoagulation have been delivered and vision is currently $20 / 300$.

\section{Fundoscopy}

At presentation, the average number of retinal quadrants involved with telangiectasia was 2.7 (range 1-4, median 3), eight of the 10 patients had retinal detachment, six of these being total, and all patients had macular involvement with either subretinal exudate or fibrosis.

At latest follow-up, six patients (patients 4, 5, 6, 7, 9 and 10) had mostly or completely attached retinas, and all demonstrated either shallow subretinal fluid, subretinal fibrosis or both. Patient $\mathrm{l}$ had a chronic inferior retinal detachment (fig 1B). Patient 2 had a phthisical eye with a complete retinal detachment with subretinal exudate and organised fibrosis as well as a white cataract. Patient 3 had recurrence of his total

Table 1 Characteristics of the 10 patients treated for Coats' disease

\begin{tabular}{|c|c|c|c|c|c|c|c|c|c|c|}
\hline No. & $\begin{array}{l}\text { Age, } \\
\text { years* }\end{array}$ & $\begin{array}{l}\text { Presenting } \\
\text { visual } \\
\text { acuity }\end{array}$ & $\begin{array}{l}\text { Latest } \\
\text { visual } \\
\text { acuity }\end{array}$ & $\begin{array}{l}\text { Number of } \\
\text { quadrants } \\
\text { with } \\
\text { telangiect- } \\
\text { asia* }^{*}\end{array}$ & $\begin{array}{l}\text { Retinal } \\
\text { detachment* }^{*}\end{array}$ & $\begin{array}{l}\text { Macular } \\
\text { findings* }\end{array}$ & Surgery & $\begin{array}{l}\text { Treatment } \\
\text { during } \\
\text { follow-up }\end{array}$ & $\begin{array}{l}\text { Follow- } \\
\text { up, } \\
\text { years }\end{array}$ & $\begin{array}{l}\text { Comments } \\
\text { and status }\end{array}$ \\
\hline 1 & 6 & $\begin{array}{l}20 / 300 \\
\text { (fig 1) }\end{array}$ & $20 / 60$ & 2 & $\begin{array}{l}\text { Inferior } \\
\text { bullous }\end{array}$ & Fibrosis & $\mathrm{V}, \mathrm{P}, \mathrm{C}$ & $\begin{array}{l}\text { TPDL } 1 \text { month } \\
\text { postop for } \\
\text { recurrent lesion }\end{array}$ & 3 & $\begin{array}{l}\text { Chronic inferior RD } \\
\text { with SR fibrosis }\end{array}$ \\
\hline 2 & 5 & NLP & NLP & 4 & $\begin{array}{l}\text { Total } \\
\text { bullous }\end{array}$ & Exudate & $V, P, C$ & None & 2.5 & $\begin{array}{l}\text { Phthisical, dense } \\
\text { white cataract }\end{array}$ \\
\hline 3 & 1.8 & $? \mathrm{LP}$ & NLP & 3 & Total & Exudate & $\mathrm{V}, \mathrm{P}, \mathrm{C}$ & $\begin{array}{l}\text { Recurrence of } \\
\text { exudative } \\
\text { detachment, } \\
\text { declined } \\
\text { further } \\
\text { treatment }\end{array}$ & 1 & \\
\hline 4 & 3 & $? \mathrm{LP}$ & NLP & 3 & $\begin{array}{l}\text { Total } \\
\text { bullous }\end{array}$ & Exudate & $V, P, C$ & None & 2 & $\begin{array}{l}\text { Periorbital cellulitis, } \\
\text { persistent SR fibrosis }\end{array}$ \\
\hline 5 & 3 & LP & NLP & 4 & Total bullous & Fibrosis & $V, P, C$ & None & 2 & Persistent SR fibrosis \\
\hline 6 & 2.5 & NLP & $\mathrm{HM}$ & 3 & $\begin{array}{l}\text { Total } \\
\text { bullous }\end{array}$ & Exudate & $\begin{array}{l}\text { 1) V, P, C } \\
\text { 2) Vt, M, } \\
\text { I, O }\end{array}$ & $\begin{array}{l}\text { Second surgery at } \\
4 \text { months for } \\
\text { persistent RD }\end{array}$ & 4.5 & $\begin{array}{l}\text { Silicone oil in-situ, } \\
\text { persistent SR fibrosis }\end{array}$ \\
\hline 7 & 7 & $\begin{array}{l}\text { CF } 1 \text { foot } \\
(30.48 \mathrm{~cm})\end{array}$ & $20 / 200$ & 2 & Temporal & $\begin{array}{l}\text { Organised } \\
\text { subretinal } \\
\text { fibrosis }\end{array}$ & Vt, R, G, I & None & 1 & \\
\hline 8 & 7 & LP (fig 2) & NLP & 4 & $\begin{array}{l}\text { Total } \\
\text { bullous }\end{array}$ & Fibrosis & $V_{t}, P, C, M$ & 3 laser & 4 & $\begin{array}{l}\text { Chronic tractional } \\
\text { detachment and } \\
\text { preretinal fibrosis }\end{array}$ \\
\hline 9 & 6 & $\begin{array}{l}\text { CF } 4 \text { feet } \\
(1.23 \mathrm{~m})\end{array}$ & $20 / 300$ & 1 & No & Fibrosis & None & 1 cryopexy & 2 & \\
\hline 10 & 4.5 & $20 / 40^{-2}$ & $20 / 300$ & 1 & No & Exudate & None & 2 laser & 1 & \\
\hline
\end{tabular}

*At time of presentation to ophthalmologist.

$C$, cryopexy; $C F$, counts fingers; $G, 15 \% C_{3} F_{8}$ gas exchange; I, indirect laser photocoagulation; $H M$, hand motions; $L P$, light perception; ? LP, presumed light perception $M$, preretinal membrane peel; NLP, no light perception; $O$, intraocular silicone oil; $P$, posterior sclerotomy with subretinal fluid drainage; $R$, retinotomy with subfovea fibrovascular membrane removal; RD, retinal detachment; SR, subretinal; TPDL, trans-pupillary diode laser; $V$, vitreous infusion; Vt, vitrectomy. 

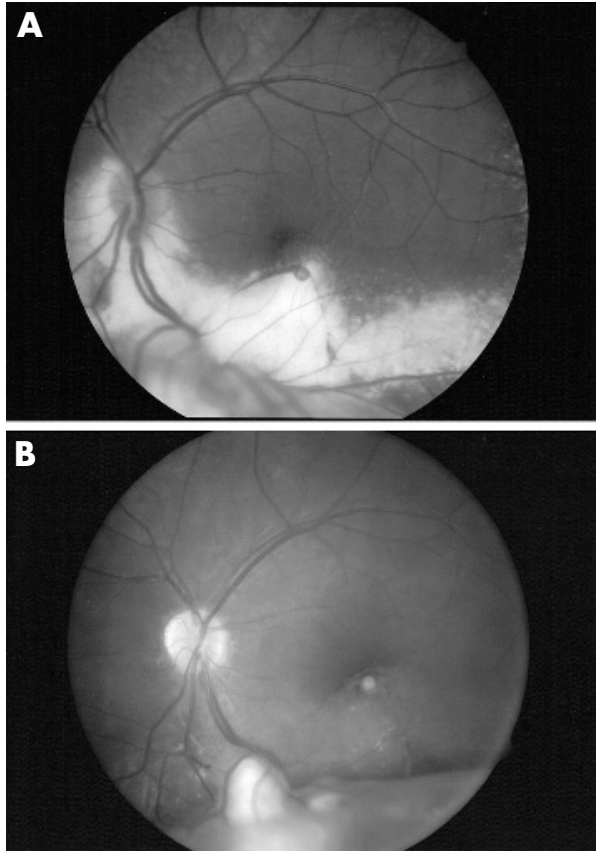

Figure 1 (A) Preoperative fundus photograph of patient 1. This 6 year old boy presented with visual acuity of $20 / 300$, two quadrants with retinal telangiectasia and inferior bullous retinal detachment with macular exudate and fibrosis. (B) Postoperative fundus photograph of patient 1 after photocoagulation. Current visual acuity is $20 / 60$ with a chronic inferior retinal detachment with subretinal fibrosis.

retinal detachment, but further treatment was declined by his parents. Patient 8 had a shallow, chronic tractional detachment caused by an organised vitreous membrane, as well as a dense white cataract (fig 2B).

No patient has had detectable recurrence of anomalous vessels since their last treatment, except for patient 6 who was discharged with persistent telangiectasia to his referring physician in Hong Kong where he underwent a second operation. No patients have developed secondary neovascular glaucoma, and all patients have kept a cosmetically acceptable, pain-free eye.

\section{DISCUSSION}

In treating Coats' disease, the clinician should address three main goals of therapy. Of paramount importance is ascertaining the correct diagnosis and ruling out retinoblastoma. This can best be achieved by a combination of clinical examination, which with Coats' shows peripheral telangiectasia with subretinal exudate, and CT scanning, which generally demonstrates the absence of intraocular calcification. ${ }^{11}{ }^{12}$ Magnetic resonance imaging and B-scan ultrasonography have also been shown to be useful in differentiating between the two diseases. ${ }^{913}$

The second objective is to prevent the development of painful neovascular glaucoma secondary to a chronic retinal detachment. This will often necessitate ablation of the vascular anomalies to enable reabsorption of any retinal detachment. Finally, after ensuring the correct diagnosis and preservation of the eye, treatment should focus on maximising useful vision.

Patients who present with retinal detachment have been treated with a variety of surgical interventions. Visual outcomes are usually dismal due to persistent foveal subretinal fluid and/ or fibrosis. ${ }^{3}{ }^{14}$ In our experience, if re-attachment is successful, promising visual outcomes seem to be more dependant on the vision at presentation than on the surgical technique employed.
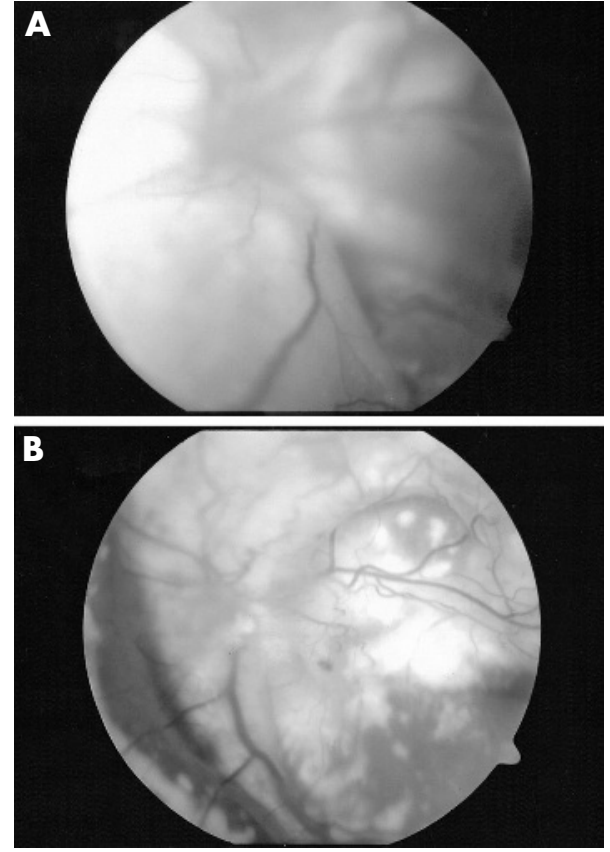

Figure 2 (A) Preoperative fundus photograph of patient 8. This 7 year old boy presented with light perception, four quadrants with retinal telangiectasia and total bullous retinal detachment with macular fibrosis. (B) Postoperative fundus photograph of patient 8 after photocoagulation. Currently the patient has no light perception with a chronic tractional retinal detachment with preretinal fibrosis and a few residual telangiectasia.

An extensive review of the literature did not yield a single report of a good visual outcome in patients presenting with NLP vision and total bullous detachment regardless of surgical method. In this series all patients with total retinal detachment had NLP or questionable LP vision at presentation, with none of them retaining useful vision. Even with successful retinal reattachment, amblyopia will hinder visual recovery as patching would be inappropriate in eyes with such profound visual loss and little hope of significant visual recovery. The only patients maintaining useful vision in this series (patients 1, 7, 9 and 10) all presented with subtotal retinal detachments if any detachment was present, had only one or two quadrants affected by telangiectasia and had better than LP vision.

Based on our experience and extensive review of the literature, we advocate a minimally invasive surgical approach to re-attach the retina as described above. The technique of sclerotomy with external subretinal fluid drainage and cryopexy applied to the telangiectasia was first described in 1970 by Harris and has since been reported in several other series with the addition of vitreous infusion to the procedure as we have described. ${ }^{3}{ }^{15} 16$

Several authors have reported more invasive techniques, including vitrectomy, posterior retinotomy, use of intraocular silicone or gas, and scleral buckling. ${ }^{17-19}$ Visual and anatomical outcomes are disappointing with these more complex and invasive techniques. We feel that this is a situation where less is more. In our experience, anatomical outcomes were not enhanced and were adversely affected by adding to and increasing the complexity of vitreous surgery.

Severe cases of Coats' disease are characterised by early onset and three or more retinal quadrants involved with telangiectasia. $^{23111517}$ Shields found that diffuse telangiectasia and exudation was predictive of poor visual outcome, and that $7 \%$ of eyes presenting with exudative detachment will eventually require enucleation. ${ }^{16}$ Although some authors have attributed 
promising visual outcomes to their therapy, we have found that this is more likely due to an early presentation of a less aggressive disease.

Similarly, Ridley reported on a series of 41 patients, among whom only five had marked improvement in visual acuity, all with less extensive disease and recent foveal involvement without fibrosis. ${ }^{15}$ Therefore, although it is tempting to use all the techniques at one's disposal, this may prove counterproductive and surgeons must recognise that the primary goal of therapy is to retain and salvage the eye. More invasive surgeries, such as vitrectomy, membrane peeling, retinotomy, use of intraocular gas or silicone oil tamponade, and scleral buckling, cause unnecessary risks for the patient for limited benefits in cases presenting with advanced disease and poor vision.

Most patients with mild disease, that is to say, peripheral retinal telangiectasis with little or no exudative detachment, generally fare well with laser photoablation alone. ${ }^{15} 1620$ These eyes need careful observation and follow-up over time, generally with repeat treatment with disease recurrence. When laser treatment alone does not suffice, we recommend treatment with the establishment of a pars plana vitreous infusion line of balanced salt solution, sclerotomy and external subretinal fluid drainage, followed by laser photoablation of the vascular anomalies and/or cryopexy. In our experience, this technique appears to yield equivalent or superior results than the more invasive procedures described above, with less risk, expense and time.

Authors' affiliations

R S Adam, Department of Ophthalmology, McMaster University, Hamilton, Canada

P J Kertes, W-C Lam, Department of Ophthalmology, University of Toronto, Toronto, Canada

Funding: No external funding was obtained for this paper.

Competing interests: None of the authors have a proprietary interest in this work.

Presented at the American Society of Retinal Surgeons, 16 July 2005, Montreal, Canada.
Correspondence to: Dr Robert Adam, Department of Ophthalmology, McMaster University, 41-1967 Main St. W. Hamilton, Ontario, Canada L8S 4P4; robertsauladam@yahoo.co

Accepted 25 September 2006

Published Online First 4 October 2006

\section{REFERENCES}

1 Coats G. Forms of retinal disease with massive exudation. Roy London Ophthal Hosp Rep 1908; 17:440-525.

2 Harris GS. Coats' disease, diagnosis and treatment. Mod Probl Ophthal 1972;10:277-85

3 Harris GS. Coats' disease, diagnosis and treatment. Can J Ophthalmol 1970;5:311-19.

4 Deutsch TA, Robb MF, Jampol LM. Spontaneous regression of retinal lesions in Coats' disease. Can J Ophthalmol 1982;17:169-72.

5 Morales AG. Coats' disease: natural history and results of treatment. Am J Ophthalmol 1965;60:855-65.

6 Reese A. Telangiectasis of the retina and Coats' disease. Am J Ophthalmol 1956;42:1-8.

7 Campbell FP. Coats' disease and congenital vascular retinopathy. Trans Am Ophthalmol Soc 1977;74:365-424.

8 Tarkkanen A, Laatikainen L. Coats' disease: clinical, angiographic, histopathological findings and clinical management. $\mathrm{Br} J$ Ophthalmol 1983:67:766-76.

9 Shields JA, Leonard BC, Michelson JB, et al. B-scan ultrasonography in the diagnosis of atypical retinoblastomas. Can J Ophthalmol 1976;11:42-51.

10 Haik BG, Koizumi J, Smith ME, et al. Fresh preparation of subretinal fluid aspirations in Coats' disease. Am J Ophthalmol 1985;100:327-8.

11 Char DH. Coats' syndrome: long term follow up. Br J Ophthalmol 2000;84:37-9.

12 Arigg P, Hedges RT, Char DH. Computed tomography in the diagnosis of retinoblastoma. $\mathrm{Br}$ J Ophthalmol 1983;67:588-91.

13 Haik BG, Saint Lovis L, Smith ME, et al. Magnetic resonance imaging in the evaluation of leukocoria. Ophthalmology 1985;92:1143-52.

14 Silodor SW, Augsburger JJ, Shields JA, et al. Natural history and management of advanced Coats' disease. Ophthalmic Surg 1988;19:89-93.

15 Ridley ME, Shields JA, Brown GC, et al. Coats' disease. Evaluation of management. Ophthalmology 1982;89:1381-7.

16 Shields JA. Classification and management of Coats' disease: the 2000 Proctor lecture. Am J Ophthalmol 2001;131:572-83.

17 Egerer I, Tasman W, Tomer TL. Coats' disease. Arch Ophthalmol 1974;92:109-12.

18 Devenyi RG. The use of perfluorocarbon liquid in the surgical repair of a bullous retinal detachment secondary to Coats' disease. Can J Ophthalmol 1998;33:385-6.

19 Yoshizumi MO, Kreiger $\mathrm{AE}$, Lewis $\mathrm{H}$, et al. Vitrectomy techniques in late-stage Coats'-like exudative retinal detachment. Doc Ophthalmol 1995:90:387-94.

20 Nucci P, Bandello F, Serafino $M$, et al. Selective photocoagulation in Coats' disease: ten-year follow up. Eur J Ophthalmol 2002;12:501-5. 